\section{P3-S1.23 MYCOPLASMA GENITALIUM IN SOUTH AFRICAN MEN WITH AND WITHOUT SYMPTOMS OF URETHRITIS: DIAGNOSIS AND BACTERIAL LOAD}

doi:10.1136/sextrans-2011-050108.423

${ }^{1} \mathrm{~A}$ Hoosen, ${ }^{2} \mathrm{M} \mathrm{C}$ le Roux, ${ }^{3} \mathrm{~A}$ Adam. ${ }^{1}$ University of Pretoria; ${ }^{2}$ University of Limpopo, Medunsa Campus, Pretoria, South Africa; ${ }^{3}$ Private Medical Practice, Silverton, Pretoria, South Africa

Objectives To diagnose causes of urethritis in symptomatic men and evaluate the role of Mycoplasma genitalium by calculating bacterial loads in urine specimens from symptomatic and asymptomatic men.

Methods Urine specimens from 94 men with visible urethral discharge, 206 with burning on micturition (BOM) and 75 without any genital symptoms were tested for $N$ gonorrhoeae (NG), $C$ trachomatis (CT), T vaginalis (TV) and M genitalium (MG) using TMA assays. The bacterial load was estimated by quantitative real-time PCR assay in specimens with $M$ genitalium alone.

Results At least one pathogen was detected in 138 (46\%); mixed infections in 28 (9.3\%). The most common mixed infection was NG + MG (3.7\%). There were significant differences for MG $(17.3 \%$ vs $6.6 \%)$, NG (16.7\% vs $2.6 \%)$, CT ( $12.3 \%$ vs $5.1 \%)$, and TV ( $8.0 \%$ vs $1.3 \%$ ) in symptomatic vs asymptomatic men. There was also a significant difference in presence of $\mathrm{MG}$ in the symptomatic men $(20.2 \%$ in men with discharge vs $4.4 \%$ in those with BOM). Patients with urethral discharge (mean $5.3 \times 103$ copies/ul) had significantly higher $M$ genitalium concentrations than those with BOM (mean $6.7 \times 102$ copies/ul) $(p<0.001)$, and the bacterial concentrations in men with symptoms and/or signs of urethritis were significantly higher than that in asymptomatic men (mean $4.6 \times 101$ copies/ul) $(\mathrm{p}=0.02)$.

Conclusions Significantly more organisms were detected in patients with urethritis than in those without. There was a strong association between $M$ genitalium bacterial load and men with symptoms of urethritis both BOM and urethral discharge. As the number of organisms increased, the severity of the symptoms increased (greater numbers in urethral discharge), indicating a role for $M$ genitalium in disease severity. This study also demonstrated the usefulness of quantitative PCR in determining an aetiological role and possibility of monitoring efficacy of treatment for this pathogen.

\section{P3-S1.24 COST EFFECTIVENESS OF SELF-TAKEN VAGINAL SWABS USING GENPROBE AC2 ASSAY VS CLINICIAN TAKEN URETHRAL AND ENDOCERVICAL SWABS FOR DETECTION OF GONORRHOEA}

doi:10.1136/sextrans-2011-050108.424

${ }^{1} \mathrm{~J}$ Wilson, ${ }^{2} \mathrm{C}$ Hulme, ${ }^{1} \mathrm{C}$ Stewart, ${ }^{1} \mathrm{~S}$ Schoeman, ${ }^{1} \mathrm{M}$ Wilcox. ${ }^{1}$ University of Leeds, Leeds, UK; ${ }^{2}$ Leeds General Infirmary, Leeds, UK

Background Culture of Neisseria gonorrhoeae from the urethral and endocervix is currently the recommended method of detecting gonorrhoea (GC) in women in the UK. This necessitates a speculum examination. NAATs are the mainstay of testing for Chlamydia trachomatis (CT) infection and assays exist which can also detect GC. NAATs are more sensitive than culture meaning non-invasive samples can be used. No previous study has compared self-taken VVS analysed by AC2 with urethral and endocervical GC culture, which is considered the gold standard test in the UK. We therefore undertook this comparison in a clinical setting with low GC prevalence and performed a cost-effectiveness analysis.

Methods Participants were recruited within the Centre for Sexual Health at Leeds, UK between March 2009 and January 2010. The women, presenting for a new visit, performed a self-taken VVS and were then examined and urethral and endocervical samples taken for
Abstract P3-S1.24 Table 1 Diagnostic test

\begin{tabular}{|c|c|c|c|c|c|}
\hline Diagnostic test & Costs & Difference & $\begin{array}{l}\text { Gonorrhoea } \\
\text { cases } \\
\text { correctly } \\
\text { diagnosed }\end{array}$ & Difference & $\begin{array}{l}\text { ICERs (£ per } \\
\text { correctly } \\
\text { diagnosed } \\
\text { case) }\end{array}$ \\
\hline $\begin{array}{l}\text { All have GC culture } \\
\text { test and CT NAAT } \\
\text { irrespective of } \\
\text { symptoms }\end{array}$ & 250841.79 & 29922.49 & 82 & 13 & $\begin{array}{l}\text { GC VVS } \\
\text { dominates }\end{array}$ \\
\hline $\begin{array}{l}\text { All have GC/CT } \\
\text { VSS irrespective } \\
\text { of symptoms }\end{array}$ & 220919.30 & & 95 & & \\
\hline
\end{tabular}

GC culture. Positive AC2 tests were confirmed by the Aptima GC and/or Aptima CT mono-specific platform tests. The cost effectiveness was analysed using incremental cost effectiveness ratios (ICERs). The analysis uses correct detection of GC as the primary endpoint and adopts the perspective of the UK National Health Service. Costs were estimated from a sub-sample of 92 patients in July 2009. The analysis includes costs of clinic time, together with the laboratory costs. Comparisons were made of self-taken VVSs using AC2 vs clinician taken cultures for the whole cohort.

Results 100 of the 3973 participants (2.5\%) were infected with GC. The overall sensitivity of GC culture was $82 \%$ and self-taken VVS $95 \% .35 \%$ of the participants were asymptomatic in whom GC culture sensitivity was 79\% and self-taken VVS 91\%. The cost effectiveness results are presented in Abstract P3-S1.24 table 1.

Conclusions Self-taken VVS analysed by AC2 are cost effective compared to urethral and endocervical GC culture; being more sensitive and less costly. Whilst those presenting with symptoms continue to require a clinician examination use of VVSs in women with no symptoms removes the need for examination. The cost of the time taken in explanation of self taken swabs for this group represents $<20 \%$ of the cost of a clinician examination. Cost savings also accrue through use of AC2 alone rather than GC culture and CT NAAT.

\section{P3-S1.25 EVALUATION OF REAL TIME PCR FOR DETECTION OF FIVE SEXUALLY TRANSMITTED DISEASES IN ABIDJAN, IVORY COAST}

doi:10.1136/sextrans-2011-050108.425

S Kakou-Ngazoa. Institut Pasteur Abidjan, Abidjan, Côte d'Ivoire

Objective To evaluate a real-time PCR assay for molecular screening of five most common sexually transmitted diseases Trichomonas vaginalis, Mycoplasma genitalium, Neisseria gonorrhoeae, Chlamydia trachomatis and Herpes simplex virus 2 in Abidjan, Ivory Coast.

Methods 25 self-collected vaginal swabs were obtained from adult persons with symptoms of vaginal discharge and vulval irritation. The samples were diluted in sterile PBS and the DNA extraction was processed using Nuclisens extraction Kit. $5 \mu \mathrm{l}$ of genome extract was applied in real-time PCR for each pathogen. The targeted region of real time was the $18 \mathrm{~S}$ ribosomal DNA genes for $T$ vaginalis and the $16 \mathrm{~S}$ rRNA for $M$ genitalium.

Results 10 of 25 (40\%) samples were positive for sexually transmitted dieases. Over $30 \%$ of the samples shown inhibition and were tested positive by serial dilution. Chlamydia trachomatis is the most detected infection in five samples, and one sample was positive respectively by $T$ vaginalis and by $N$ gonorrhoeae. We detect no coinfection in all samples.

Conclusions The real-time PCR is a suitable specific and sensitive method to investigate and to detect sexually transmitted diseases in developing countries. 